\title{
Glycogen Storage Disease Type V
}

National Cancer Institute

\section{Source}

National Cancer Institute. Glycogen Storage Disease Type V. NCI Thesaurus. Code C84738.

An autosomal recessive inherited type of glycogen storage disease caused by deficiency of myophosphorylase. It results in myalgias, muscle cramping and stiffness, and exercise intolerance. 